\title{
Mutation screening of the UBE3A gene in Chinese Han population with autism
}

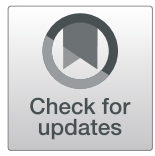

\author{
Xue Zhao, Ran Zhang and Shunying Yu
}

\begin{abstract}
Background: 15q11-13 region is one of the most complex chromosomal regions in the human genome. UBE3A is an important candidate gene of autism spectrum disorder (ASD), which located at the 15q11-13 region and encodes ubiquitin-protein ligase E3A. Previous studies about UBE3A gene and ASD have shown inconsistent results and few studies were performed in Chinese population. This study aimed to detect the genetic mutations of UBE3A gene in Chinese Han population with ASD and analyze genetic association between these variants and ASD.

Methods: The samples consisted of 192 patients with autism according to the DSM-IV diagnostic criteria and 192 healthy controls. We searched for mutations at coding sequence (CDS) regions and their adjacent non-coding regions of UBE3A gene using the high resolution melting (HRM) and Sanger sequencing methods. We further increased sample size to validate the detected variants using HRM and conducted association analysis between case and control groups.

Results: A known single nucleotide polymorphism ( $>$ > C, rs150331504) located at the CDS4 and a known 5 bp insertion/ deletion variation (AACTC+/-, r571127053) located at the intron region of the upstream 288 bp of the CDS2 of UBE3A gene were detected using Sanger sequencing method. The ASD samples of case group were 391 for rs 71127053,384 for rs150331504 and 384 healthy controls, which were used to make an association analysis. The results of association analysis suggested that there were no significant difference about the allele and genotype frequencies of rs 71127053 and rs150331504 between case and control groups after extending the sample size. Besides, rs150331504 is a synonymous mutation and we compared the secondary structure and minimum free energy (MFE) of mRNA harboring the allele T or C of rs150331504 using RNAfold software. We found that the centroid secondary structure apparently differs along with the polymorphisms of rs150331504 T > C, the results suggested that this variant might change the secondary structure of mRNA of UBE3A gene. We did not detect mutations in other coding regions of UBE3A gene.
\end{abstract}

Conclusions: These findings showed that UBE3A gene might not be a major disease gene in Chinese ASD cases.

Keywords: ASD, 15q11-13, UBE3A, HRM, Sequencing

\section{Background}

Autism is a childhood-onset neurodevelopmental disorder characterized by impaired social interactions and communication, restricted interests and repetitive behaviors, the onset of autism is usually before 3 years old. In 2013, the fifth edition of Diagnostic and Statistical

\footnotetext{
* Correspondence: yushuny@yahoo.com

Shanghai Mental Health Center, Shanghai Jiao Tong University School of Medicine, 600 Wanping Nan Road, Shanghai 200030, China
}

Manual of Mental Disorders (DSM-5) removed delayed language development from the list of diagnose criteria, autism covered a host of diseases such as Asperger's disorder, childhood disintegrative disorder, and pervasive developmental disorder not otherwise specified and redefined itself as autism spectrum disorder (ASD) [1]. Along with changes in diagnosis criteria and improved understanding and awareness about this disease, the prevalence of ASD increased in the past decade according to the report of Centers for Disease Control and

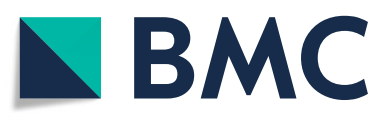

(c) The Author(s). 2020 Open Access This article is licensed under a Creative Commons Attribution 4.0 International License, which permits use, sharing, adaptation, distribution and reproduction in any medium or format, as long as you give appropriate credit to the original author(s) and the source, provide a link to the Creative Commons licence, and indicate if changes were made. The images or other third party material in this article are included in the article's Creative Commons licence, unless indicated otherwise in a credit line to the material. If material is not included in the article's Creative Commons licence and your intended use is not permitted by statutory regulation or exceeds the permitted use, you will need to obtain permission directly from the copyright holder. To view a copy of this licence, visit http://creativecommons.org/licenses/by/4.0/ The Creative Commons Public Domain Dedication waiver (http://creativecommons.org/publicdomain/zero/1.0/) applies to the data made available in this article, unless otherwise stated in a credit line to the data. 
Prevention of USA [2]. The worldwide population prevalence is about $1 \%$ [3]. The estimated prevalence of ASD in Chinese population ranged from 2.8 to 29.5 per 10 , 000 persons according to a review that summarized the findings in Chinese population from several areas [4]. Although epidemiological studies have found a number of risk factors for ASD, such as maternal pregnancy and pregnancy complications $[5,6]$, the cause of ASD is not clear. Multiple twin and family studies have confirmed that genetic factors play an important role in the development of ASD and the heritability is about 90\% [7]. Recent genetic studies have found that hundreds of genetic variants, including common and rare variants, contributing to the occurrence of ASD.

$15 \mathrm{q} 11-\mathrm{q} 13$ is a very complex chromosomal region and one of the most likely to occur abnormal regions in the genome, which is associated with a variety of neuropsychiatric diseases such as mental retardation and obsessive compulsive disorder [8]. The 15q11-q13 region consists of a large proximal domain $(\sim 2 \mathrm{Mb})$ of paternally expressed genes, a smaller maternal expression domain (MED: $\sim 500 \mathrm{~kb}$ ), and a large distal region $(\sim 2 \mathrm{Mb})$ of apparently biallelic expression [9]. Individuals with duplications of the 15q11-q13 region caused by inverted duplication of an extra 15q11-13 (dup15) or isodicentric chromosome 15 [idic (15)] show autism features. Moreover, the incidence of maternally inherited 15q11-13 duplications in ASD population is about $1-3 \%$, which is considered the most common copy numbers variants (CNVs) in ASD [10]. UBE3A gene is an imprinted, maternally expressed gene which resides on the MED of 15q11-13 region. UBE3A gene encodes the E6-AP ubiquitin-protein ligase and is the causative gene in Angelman syndrome (AS), point mutations in $U B E 3 A$ gene were discovered in about $10 \%$ cases of AS [11]. AS is also a neurodevelopmental disorder characterized by severe motor and intellectual retardation, ataxia, hypotonia, epilepsy, absence of speech, and characteristic facies. Previous studies have shown that autistic-like features was frequently described in AS patients, this was considered AS comorbid ASD [12, 13]. Overall, $U B E 3 A$ gene was identified as an important candidate gene of ASD.

However, recent studies about $U B E 3 A$ gene and ASD have shown inconsistent results. In the earlier researches, Cook et al. [14] examined multiallelic transmission disequilibrium test (MTDT) on multiple markers of $U B E 3 A$ gene in autistic disorder families, no correlation between these markers and autism was found. Nurmi et al. [15] reported that $U B E 3 A$ gene was associated with autism for the first time, the researchers detected a significant linkage disequilibrium between the D15S122 marker located in UBE3A gene and autism in 94 autistic families. Subsequently, Nurmi et al. [9] conducted linkage disequilibrium analysis on multiple single nucleotide polymorphism (SNPs) and genetic markers of $U B E 3 \mathrm{~A}$ gene in 100 families with autism, but the researchers failed to find evidence for D15S122 marker related to autism. Glessner et al. [16] conducted genome-wide CNVs screening in autism patients and healthy control, found that autism patients carried CNVs in multiple genes of ubiquitin system (UBE3A, PARK2, $R F W D 2$ and $F B X O 40$ ). In terms of rare mutation screening, Veenstra-VanderWeele et al. [17] conducted mutation screening in the exons and promoters of $U B E 3 A$ gene in 10 patients with autism, suggested no functional mutations that changed amino acid sequence. Schaaf et al. [18] screened mutations in 21 autism candidate genes including UBE3A gene in 339 high-functioning ASD, found non-synonymous mutations in $U B E 3 A$ gene of ASD patients. In the recent studies, Lossifov et al. [19] conducted a whole genome sequencing study in more than 2517 ASD simplex families, found that an autism proband with a T485A missense mutation in $U B E 3 A$ gene. Yi et al. [20] reported that T485A disrupts phosphorylation regulation, hyperactivates UBE3A and increases synapse formation in vivo. In studies of animal model, Nakatani et al. [21] found that the expression level of Ube3a gene in matDp/+ mice increased nearly 2 times. To explore the relationship between the dose effect of Ube3a gene and autism phenotype, Smith et al. [22] identified that the penetrance rate of autism phenotype in mice carrying $U b e 3 a$ gene triplication was significantly higher than the mice with $U$ Ube3a gene duplication.

Given that $U B E 3 A$ gene is one important candidate gene of ASD and there was few studies about $U B E 3 A$ gene in Chinese Han people with ASD, we conducted mutation screening for coding region of $U B E 3 A$ gene and aimed to explore the relationship between these mutations and ASD.

\section{Methods \\ Subjects}

Firstly, the mutation screening research was conducted on 192 children who were diagnosed as autism and 192 heathy controls subjects called as the primary sample set (the detailed information see Table 3). Then, we further expanded the sample size called as the second set (comprising the primary sample set, 192 cases and 192 controls) (the detailed information see Table 3) for an association study. The patients were fulfilling the criteria for the diagnosis of autism according to the 4th edition of the Diagnostic and Statistical Manual of Mental Disorders (DSM-IV). They were recruited from Shanghai Mental Health Center, Shanghai Jiao Tong University School of Medicine. Patients were excluded if they had known mental and physical illness or chromosomal 
abnormalities. The healthy controls subjects were volunteers recruited by advertisement from Shanghai Mental Health Center and local community, and brief unstructured interview were evaluated by senior psychiatrists to exclude individuals who suffer from any severe physical diseases, as well as personal and family history of mental diseases. All subjects are Chinese Han descendant. Ethical approval was obtained from the ethics committees of Shanghai Mental Health Center and an informed written consent of participation in the study was signed by the parents or the legal guardians of the studied subjects.

\section{Gene screening}

Five milliliters of the whole blood was taken and ethylenediaminetetraacetic acid (EDTA) was used to be anticoagulant. DNA was isolated according to the established laboratory protocols.

Sequencing data were aligned to the annotated human genome sequence (hg19) using the BLAT tool of the UCSC Genome Browser (http://genome.ucsc.edu/). The $U B E 3 A$ gene sequence was searched from the UCSC Genome Browser database, which showed that there were three spliceosomes (NM_130838, NM_000462 and NM_130839) of UBE3A gene. The sequence information of spliceosome 2 includes spliceosome 1 (NM_130838) and 3 (NM_130839). Therefore, the sequence information of spliceosome 2 (NM_000462) was selected as the candidate sequence. $U B E 3 A$ gene has 14 exons (Fig. 1), exon $1,2,3$, initiation $36 \mathrm{bp}$ of exon 4 and the terminal $1888 \mathrm{bp}$ of exon 14 are non-coding regions (untranslated regions, UTR), the terminal 29 bp of the exon 4 , exon 5 , $6,7,8,9,10,11,12,13$ and initiation $121 \mathrm{bp}$ of exon 14 are coding sequence (CDS) (Fig. 1). In this study, we performed mutation screening for all coding regions and their adjacent non-coding regions named by CDS1CDS11, the length of CDS1-CDS11 are $29 \mathrm{bp}, 42 \mathrm{bp}$, 299 bp, 1247 bp, 145 bp, 206 bp, 165 bp, 156 bp, 74 bp, $144 \mathrm{bp}, 121 \mathrm{bp}$, respectively. The total sequenced length after amplifying was $6273 \mathrm{bp}$ (see Tables 1 and 2).

The two methods high resolution melting (HRM) and Sanger sequencing were performed in our study. The HRM method was used to detect CDS 3, 8, 9, 10 and 11, and the CDS 1,2,4,5,6,7 were directly sequenced by Sanger method according to the amplicon length of every CDS after a series of preliminary experiments. The found variants were further detected in the expanded samples using the HRM method and performed followup analyses.

\section{HRM analysis}

The CDS 3, 8, 9, 10 and 11 were amplified using polymerase chain reaction (PCR) and the primers information summarized in Table 1 . The primers were designed to generate amplicons of $200-400 \mathrm{bp}$. Then HRM were performed using LightCycler ${ }^{\circ} 96$ Instrument (Roche Diagnostics, Roche Instrument Center AG, Rotkreuz, Switzerland). The amplifications test were performed in $10 \mu \mathrm{L}$ volumes containing $10 \mathrm{ng}$ of genomic DNA, $2 \mu \mathrm{mol} / \mathrm{L}$ primers, $2.5 \mathrm{mmol} / \mathrm{L} \mathrm{MgCl} 2$ and $5 \mu \mathrm{L} 2 \mathrm{X}$ LightCycler 96 High Resolution Melting Master (Roche Diagnostics) buffer. PCR cycling included an initial preincubation at $95^{\circ} \mathrm{C}$ for $10 \mathrm{~min}$, followed by 45 cycles of 10 s at $95^{\circ} \mathrm{C}$, from $65^{\circ} \mathrm{C}$ to a "touchdown" at $55^{\circ} \mathrm{C}$, and $30 \mathrm{~s}$ at $72^{\circ} \mathrm{C}$. The melting program included three steps: denaturation at $95^{\circ} \mathrm{C}$ for $10 \mathrm{~s}$, renaturation at $65^{\circ} \mathrm{C}$ for 1 min, and a subsequent melting cycle consists of a continuous fluorescent reading from $60^{\circ} \mathrm{C}$ to $90^{\circ} \mathrm{C}$ at a rate of 25 acquisitions per ${ }^{\circ} \mathrm{C}$. The detected mutations were confirmed with an independent PCR and bidirectional sequencing.

\section{Sanger sequencing}

CDS 1, 2, 4, 5, 6 and 7 were directly sequenced using Sanger method, which could detect about $800 \mathrm{bp}$ sequence length. The length of CDS4 was $1247 \mathrm{bp}$, which was sequenced forward and backward. The PCR primers information were listed in Table 2. Each PCR master mix included $2 \mu \mathrm{M}$ of each primer, $1 \mu \mathrm{l}$ mix dNTP, $1.5 \mu \mathrm{l}$ $\mathrm{MgCl} 2,5 \mu \mathrm{l}$ of $10 \times$ PCR buffer, (5 U/ $\mu \mathrm{l})$ AmpliTaq Gold DNA polymerase, $3 \mu \mathrm{l}$ of DNA sample, and doubledistilled water to reach the total volume of $50 \mu$ l. PCR condition contained initial denaturation at $95^{\circ} \mathrm{C}$ for 5 min, 30 cycles of $95^{\circ} \mathrm{C}$ for $30 \mathrm{~s}$ and $62^{\circ} \mathrm{C}-65^{\circ} \mathrm{C}$ for $30 \mathrm{~s}$ and $72{ }^{\circ} \mathrm{C}$ for $45 \mathrm{~s}$, then $72{ }^{\circ} \mathrm{C}$ for $5 \mathrm{~min}$ as final extension was performed. After purification of PCR products using TaKaRa ${ }^{\circ}$ Shrimp Alkaline Phosphatase (SAP) and ExonucleaseI (ExonI), sequencing was performed by BigDye Terminator Kit (Applied Biosystems, USA) according to the method by Sanger F, et al. [23]. The sequence information were read using Applied Biosystems (ABI) 3130 Genetic Analyzer (Applied Biosystems, USA). As well,

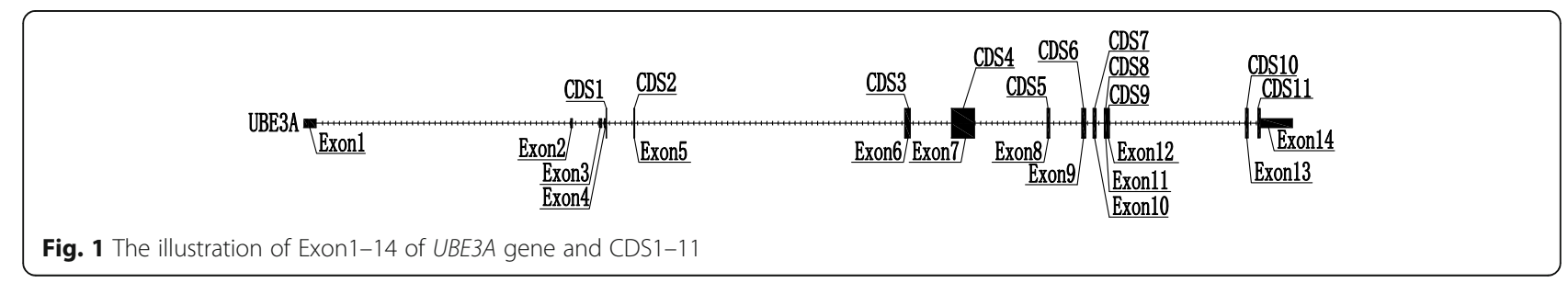


Table 1 The primer information for HRM

\begin{tabular}{|c|c|c|c|}
\hline CDS & & Primer sequence & Amplicon length (bp) \\
\hline \multirow[t]{2}{*}{3} & Forward & TCCCACATGGTTITCAGGCA & 397 \\
\hline & Reverse & GAGAGCTGTACTAATCACTGTGC & \\
\hline \multirow[t]{2}{*}{8} & Forward & TITGGAGACACCTGCTITCTTA & 251 \\
\hline & Reverse & GCAGCCCAATAACTTGTGTTTTGT & \\
\hline \multirow[t]{2}{*}{9} & Forward & GTCTGAAGCAAAATCACACACCC & 256 \\
\hline & Reverse & ATATGTGGAAGCCGGGTAAGAA & \\
\hline \multirow[t]{2}{*}{10} & Forward & ACGAGGAATGCAAGGTITCG & 242 \\
\hline & Reverse & ATGAATGCCAAACTGAAACCAGTA & \\
\hline \multirow[t]{2}{*}{11} & Forward & GTACTGGGACACTATCACCACC & 285 \\
\hline & Reverse & TTTCCCATGACTTACAGTTTTCCTG & \\
\hline
\end{tabular}

the detected mutations were confirmed with an independent PCR and bidirectional sequencing.

\section{Association analysis}

For each detected variant, we further expanded the sample size of case and control groups, the case-control genotyping studies and association analysis were performed.

The statistic power was calculated using QUANTO software (version 1.2.4.) for allele of the detected variants. The parameters were set to the prevalence of autism to be $1 \%$ and a moderate odds ratio (OR) to be $1.3-$ 1.5 , the inheritance model was set as log-additive and a type I error rate of 0.05 (two-sided).

Each detected variant were genotyped using HRM method in the expanding samples.

For the association analysis, the online software SHEsis [24] (http://analysis2.bio-x.cn/myAnalysis.php) was used to compare the allelic and genotypic frequencies between the case and control groups. Another online software SNPStats [25] (http://bioinfo.iconcologia.net/snpstats/start.htm) was used to calculate the association between the detected variants and the risk of autism under 5 inheritance models, including codominant, dominant, recessive, overdominant and log-additive models. All of the statistical tests were two-sided, and $p<0.05$ was defined as statistically significant.

\section{Results}

\section{Results of mutation screening}

HRM method was used to detect mutations of CDS $3,8,9,10,11$ and the results indicated that there were not mutations in $\operatorname{CDS} 3,8,9,10$ and 11 in our tested samples.

The known insertion deletions (AACTC+/-, rs71127053) in the upstream 288 bp of CDS 2 and the synonymous mutation located on CDS4, rs150331504(T>C) were found in the both case and control groups using Sanger sequencing method. The frequencies of rs71127053 in the case and control groups were both 16/192 (0.083), 4/192 (0.02) in the case group and 1/192 (0.005) in the control group carried rs150331504 in our screening samples.

Table 2 The primer information for Sanger Sequencing

\begin{tabular}{|c|c|c|c|}
\hline CDS & & Primer sequence & Amplicon length (bp) \\
\hline \multirow[t]{2}{*}{1} & Forward & GGTCTTGATTTGAATCGCAGAAA & 779 \\
\hline & Reverse & CATTGACACCTAATTTGAAGCTTTG & \\
\hline \multirow[t]{2}{*}{2} & Forward & ATTTGCTTCTGCATCTTTCACTCT & 639 \\
\hline & Reverse & TGTTGTATGGCCACCTGATCT & \\
\hline \multirow[t]{2}{*}{4} & Forward & TCCATGTGTTCCTATGCTATATGGT & 1466 \\
\hline & Reverse & TGAGCCTAGAATGTTTGGCTGT & \\
\hline \multirow[t]{2}{*}{5} & Forward & CAGTCATGATGTGTGATTCTGGGT & 603 \\
\hline & Reverse & TTCCATGTCCTGTGTAGTCCAG & \\
\hline \multirow[t]{2}{*}{6} & Forward & AGGCACACTCGTTGTAACTACC & 800 \\
\hline & Reverse & CCGATGCCACCAAATTACTTACT & \\
\hline \multirow[t]{2}{*}{7} & Forward & GGGCTITAGTGCCCAACTGTG & 555 \\
\hline & Reverse & GGGACATCACAGTGACTGACAAT & \\
\hline
\end{tabular}




\section{Results of association analysis}

The case subjects were 391 for rs71127053, 384 for rs150331504 and control subjects were both 384 (the detailed information see Table 3) after expanding the sample size in the association analysis. The MAF for rs71127053 and rs150331504 were 0.1276 and 0.0103 , and the power to detect a true risk variant in our samples were $42.3-79.8 \%$ and $8.5-14 \%$ according to OR from 1.3 to 1.5 , respectively.

The results of association analysis for rs71127053 and rs150331504 revealed that there was no significant differences in the distribution of allele (rs71127053: $p=$ 0.697, $\quad \mathrm{OR}=1.096, \quad 95 \% \mathrm{CI}=0.691-1.739 ; \quad \mathrm{rs} 150331504$ : $p=0.194, \mathrm{OR}=2.013,95 \% \mathrm{CI}=0.68-5.918)$ and genotype (rs71127053: $p=0.134$; rs150331504: $p=0.192$ ) frequencies between the case and control groups (Table S1, see Additional file 1). The genotypes frequencies of rs71127053 showed no significant association with autism under 5 inheritance models $(p>0.05)$ (Table 4).

\section{Bioinformatics analyses}

The 1000 genome project database showed that rs150331504 was a synonymous mutation, which has been shown to be functional by altering the mRNA secondary structure [26]. Although association analysis results showed that there were no significant differences about the allele and genotype distributions of rs150331504 between the case and control groups, the case group carried the mutation frequency had obvious increasing trend. Therefore, the online analysis software RNAfold (http://rna.tbi.univie.ac.at//cgi-bin/RNAfold.cgi/) was used to predict the secondary structure and minimum free energy (MFE) of mRNA harboring the allele $\mathrm{T}$ or $\mathrm{C}$ of rs150331504. RNAfold prediction result revealed that the centroid secondary structure was markedly changed with rs150331504 $\mathrm{T}>\mathrm{C}$ alleles (Fig. 2). The MFE of rs150331504 $\mathrm{T}>\mathrm{C}$ alleles centroid secondary structure was changed from $-47 \mathrm{kcal} / \mathrm{mol}$ to $-52.8 \mathrm{kcal} / \mathrm{mol}$.

\section{Discussion}

$U B E 3 A$ gene is a maternal imprinted gene located in 15q11-13, which encoded ubiquitin-protein ligase E3A that played an important role in the ubiquitin pathway. E3A ubiquitin-protein ligase is an important part of the
Table 4 Genotype comparison of rs71127053 under different inheritance models

\begin{tabular}{lllll}
\hline Model & Genotype & OR(95\%Cl) & $P$-value & AIC \\
\hline Codominant & 11 vs 12 & $0.92(0.54-1.58)$ & 0.31 & 1001.6 \\
& 11 vs 22 & $4.83(0.50-47.07)$ & & \\
Dominant & 11 vs $12-22$ & $1.02(0.61-1.72)$ & 0.94 & 1002 \\
Recessive & $11-12$ vs2 2 & $4.87(0.50-47.39)$ & 0.13 & 999.7 \\
Overdominant & $11-22$ vs1 2 & $0.91(0.53-1.56)$ & 0.74 & 1001.9 \\
Log-additive & - & $1.11(0.69-1.78)$ & 0.66 & 1001.8 \\
\hline
\end{tabular}

11 represents the wild-type homozygote, 12 represents the mutant heterozygote, and 22 represents the mutant homozygote; OR Odds ratio, $\mathrm{Cl}$ Confidence interval

ubiquitin-proteasome system. The ubiquitin-protein ligase consists of 865 amino acids and its C-terminal is a carboxyl-terminal homologous domain (homologous to the E6-AP carboxyl terminus, HECT) of E6-AP. This domain can transfer ubiquitin to the target protein through the ubiquitin-proteasome system to degrade the protein. Ubiquitin is a post-translational modification process that can quickly change the function of the protein, resulting proteasome-mediated degradation of the target protein. With the support of ubiquitin activating enzyme (E1) and ubiquitin binding enzyme (E2), ubiquitin ligase can covalently bind ubiquitin molecules and enzyme substrates. This post-translational modification process can affect a series of biological processes, including protein localization, transport, endocytosis, protein-protein interaction and protein degradation. All these processes depend on the binding of the topological structure of the ubiquitin chain to the substrate protein [27]. In the nervous system, ubiquitin-proteasome system can regulate the function of presynaptic and postsynaptic, including the release of neurotransmitters, the recirculation of synaptic vesicles at the ends of presynaptic, and dynamic change of dendritic spines and postsynaptic density [28]. UBE3A has also been shown to regulate synaptic plasticity, learning and memory formation [29].

Previous studies identified that $U B E 3 A$ gene was an important candidate gene of autism, but there are few studies about the relationship between this gene and ASD in Chinese Han population. Based on the genetic model of common disease rare variants (CDRV), our study investigated the role of $U B E 3 A$ gene variants in

Table 3 The information of primary sample set and second sample set

\begin{tabular}{|c|c|c|c|c|c|}
\hline & \multicolumn{2}{|c|}{ Primary sample set } & \multicolumn{3}{|c|}{ Second sample set } \\
\hline & cases & controls & $\begin{array}{l}\text { cases } \\
\text { (rs71127053) }\end{array}$ & $\begin{array}{l}\text { cases } \\
(150331504)\end{array}$ & controls \\
\hline Total & 192 & 192 & 391 & 384 & 384 \\
\hline Males/Females & $154 / 38$ & $147 / 45$ & $304 / 87$ & $299 / 85$ & 273/111 \\
\hline Mean age $\pm S D$ & $5.65 \pm 3.04$ & $31.59 \pm 19.01$ & $5.00 \pm 2.99$ & $5.56 \pm 2.92$ & $31.49 \pm 18.89$ \\
\hline
\end{tabular}

SD Standard deviation 

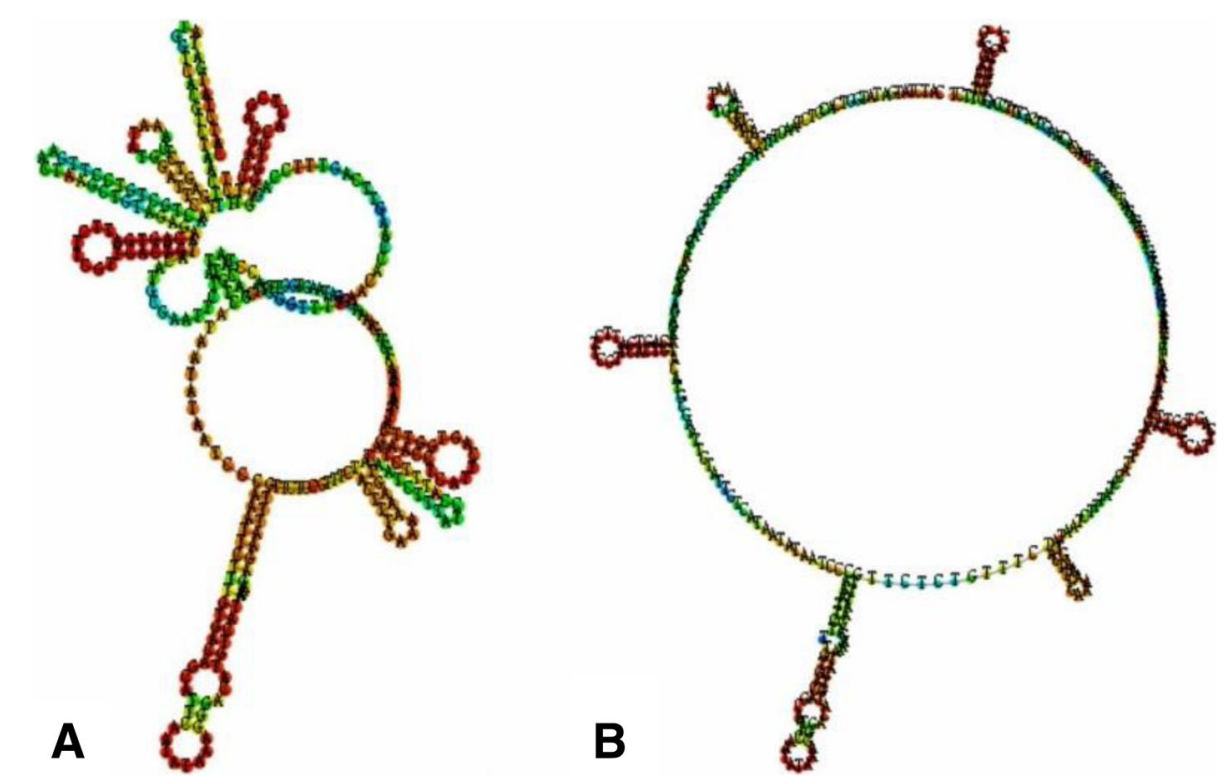

Fig. 2 a Centroid secondary structure of rs150331504 C allele; b Centroid secondary structure of rs150331504 T allele

the pathogenesis of autism in Chinese Han population. Firstly, 192 patients meeting the diagnostic criteria of DSM-IV about autism and 192 healthy controls were included, $U B E 3 \mathrm{~A}$ gene was selected as the candidate gene to conduct mutation screening on its coding region and adjacent non-coding regions. We found a known variant rs71127053 (AACTC+/-) on the upstream $288 \mathrm{bp}$ of CDS2. Subsequently, we expanded the sample size and conducted an association analysis. The results revealed that there was no significant difference on the distribution frequencies of allele and genotype of rs71127053 between the case and control groups, rs71127053 did not increase the risk of autism under different inheritance models.

Another known variant rs150331504 $(\mathrm{T}>\mathrm{C})$ was detected in the CDS4 region. Similarly, we expanded the sample size and subsequent association analysis showed no significant difference in allele and genotype distribution frequencies of rs150331504 between the case and control groups. The 1000 genome project database showed that rs150331504 was a synonymous mutation. It was generally believed that the non-synonymous mutations can change the amino acid coding sequence, which were related to disease. However, previous studies found that non-synonymous SNPs and synonymous SNPs had the same effect on diseases incidence [30]. Nackley et al. [26] found that synonymous mutations would lead to mRNA structure change, and the most stable structure was associated with the lowest protein level and reduced enzyme activity. In our study, the frequency of rs150331504 was significantly increased in the case group (4/192) compared with the control group (1/
192). Considering the role of synonymous mutations in transcription and translation, we compared the secondary structure and MFE of mRNA harboring the allele $\mathrm{T}$ or $\mathrm{C}$ of rs150331504. We found that the centroid secondary structure apparently differs along with the polymorphisms of rs150331504 $\mathrm{T}>\mathrm{C}$, the results suggested that this variant might change the secondary structure of mRNA of UBE3A gene and influence its biological functions.

We did not detected any mutations other than the two known variants and the association analysis about the two variants did not find significant difference between ASD cases and controls, which might be due to the following reasons for the negative results. Firstly, we searched the results of genome-wide association analysis (GWAS) for autism in the Psychiatric Genomics Consortium database, no positive sites for $U B E 3 A$ gene were found to be associated with autism at the genome-wide level. These results might suggest that common variants in the $U B E 3 A$ gene were not associated with autism. In addition, inadequate power as a reason of negative findings in genetic association studies must be considered. Though we have expanded the sample size and our sample size is relatively larger compared with the previous association studies about $U B E 3 A$ and ASD, it was still small and difficult to detecting the two variants with relatively low MAF, especially the MAF of rs150331504 was only 0.0103 . Although the sample size was one limitation, our study could extend the understanding about the role of $U B E 3 A$ gene in different population and provide some references for future research. Certainly, to achieve a definitive conclusion, the lager study sample 
size and different ethnic population is imperative. Considering that the role of UBE3A in synaptic plasticity, learning and memory formation and $U B E 3 A$ as a candidate gene for ASD is fairly new, more genetics and mechanisms investigations regarding $U B E 3 A$ gene and ASD should be explored in future. Moreover, we used DnaSP 5.0 software to calculate the nucleotide diversity of the $2628 \mathrm{bp}$ coding region of $U B E 3 A$ gene, and the $\pi$ value was only $3.8 \times 10^{-4}$, indicating that the mutation probability of $U B E 3 A$ gene was very low, it is very difficult to detect mutations. At last, previous studies have confirmed that CNVs in 15q11-13 region was related to the risk of autism, indicating that compared with point mutations, structural variants might more easily change the gene function and lead to the occurrence of disease.

HRM and Sanger sequencing were used in our study simultaneously and the two methods was complementary. Currently, HRM has been widely used in SNP typing, mutation screening and epigenetic studies, which is convenient, fast and much cheaper than sequencing technology. Tindall et al. [31] reported that sequences carrying one or more heterozygotes could be effectively distinguished from wild-type by HRM. HRM is widely used in the research of various diseases, especially tumor diseases. In the study of ASD, Kovac et al. [32] used this method to study the three genes SOD1, SOD2 and SOD3 and analyzed the relationship between these genes and ASD successfully. However, HRM also has some limitations. For example, the length of amplicons cannot be too long. Different from sequencing methods, the results of HRM experiment is the melting curve, which needs to be analyzed by software and draw a conclusion, so there would be some deviation in the interpretation of the result. Sequencing technology is the "gold standard" for mutation screening research at present. With the continuous emergence of second-generation sequencing and third-generation sequencing, it has been more and more favored by researchers. However, sequencing technology is very expensive, if HRM and sequencing technology were combined in one study, the total cost will be lower.

\section{Conclusions}

In this study, we investigated the role of $U B E 3 A$ gene in ASD by comprehensive screening for coding sequence regions and their adjacent non-coding regions of $U B E 3 A$ gen for mutations. The results showed that there was no association between the two detected known variants rs150331504 and rs71127053 and ASD. We found that the polymorphisms of rs150331504 $\mathrm{T}>\mathrm{C}$ might change the secondary structure of mRNA of $U B E 3 A$ gene. We did not detect mutations in other coding regions of $U B E 3 A$ gene. These findings showed that $U B E 3 A$ gene may not play an important role in our ASD cohort.

\section{Supplementary Information}

The online version contains supplementary material available at https://doi. org/10.1186/s12888-020-03000-5.

Additional file 1: Table S1. The allele and genotype distributions of rs71127053 and rs150331504 in ASD patients and healthy controls.

\begin{abstract}
Abbreviations
ASD: Autism spectrum disorder; CDS: Coding sequence; HRM: High resolution melting; MFE: Minimum free energy; DSM-5: The fifth edition of Diagnostic and Statistical Manual of Mental Disorders; MED: Maternal expression domain; [idic (15)]: Isodicentric chromosome 15; CNVs: Copy number variants; AS: Angelman syndrome; MTDT: Multiallelic transmission disequilibrium test; SNP: Single nucleotide polymorphism; DSM-IV: The 4th edition of the Diagnostic and Statistical Manual of Mental Disorders; EDTA: Ethylenediaminetetraacetic acid; UTR: Untranslated regions; PCR: Polymerase chain reaction; SAP: Shrimp Alkaline Phosphatase; Exonl: Exonucleasel; SD: Standard deviation; OR: Odds ratio; Cl: Confidence interval; HECT: Homologous to the E6-AP carboxyl terminus; CDRV: Common disease rare variant; GWAS: Genome-wide association analysis
\end{abstract}

\section{Acknowledgements \\ Not applicable.}

\section{Authors' contributions}

ZX were responsible for writing and revising the article, as well as the experiment design and statistical methods. ZR were responsible for the guidance on experiment design. YS were responsible for the participant enrolment and the management and quality control of the research process. All authors gave their scientific contribution and have approved the final manuscript.

\section{Funding}

The research was supported by National Program on Key Basic Research Project (973 Program) (Grant No. 2012CB517900). The funding body had no role in the study design; data collection, analysis, or interpretation; writing the manuscript; or the decision to submit the paper for publication.

\section{Availability of data and materials}

The datasets used and/or analyzed during the current study are available from the corresponding author on reasonable request.

\section{Ethics approval and consent to participate}

Ethical approval was obtained from the ethics committees of Shanghai Mental Health Center and all participants and the parents or the legal guardians have written informed consent.

\section{Consent for publication}

Not applicable.

\section{Competing interests}

The authors declare that they have no conflict of interest. All the authors certify that the submission is an original work and it is not under review at any other journal.

Received: 5 July 2020 Accepted: 3 December 2020

Published online: 11 December 2020

\section{References}

1. Doernberg E, Hollander E. Neurodevelopmental disorders (ASD and ADHD): DSM-5, ICD-10, and ICD-11. CNS Spectr. 2016;21(4):295-9.

2. Baio JWL, Christensen DL, Maenner MJ, Daniels J, Warren Z, Kurzius-Spencer $\mathrm{M}$, et al. Prevalence of autism Spectrum disorder among children aged 8 years - autism and developmental disabilities monitoring network, 11 sites, United States, 2014. MMWR Surveill Summ. 2018;67(6):1-23.

3. Lai MC, Lombardo MV, Baron-Cohen S. Autism. Lancet. 2014;383(9920):896910.

4. $\quad$ Feng L, Li C, Chiu H, Lee TS, Spencer MD, Wong JC. Autism spectrum disorder in Chinese populations: a brief review. Asia Pac Psychiatry. 2013; 5(2):54-60. 
5. Brown AS, Sourander A, Hinkka-Yli-Salomaki S, McKeague IW, Sundvall J, Surcel HM. Elevated maternal C-reactive protein and autism in a national birth cohort. Mol Psychiatry. 2014;19(2):259-64.

6. Gardener H, Spiegelman D, Buka SL. Prenatal risk factors for autism: comprehensive meta-analysis. Br J Psychiatry. 2009;195(1):7-14.

7. Ratajczak HV. Theoretical aspects of autism: causes--a review. J Immunotoxicol. 2011;8(1):68-79.

8. Delorme R, Moreno-De-Luca D, Gennetier A, Maier W, Chaste P, Mossner R, et al. Search for copy number variants in chromosomes 15q11-q13 and 22q11.2 in obsessive compulsive disorder. BMC Med Genet. 2010;11:100.

9. Nurmi EL, Amin T, Olson LM, Jacobs MM, McCauley JL, Lam AY, et al. Dense linkage disequilibrium mapping in the 15q11-q13 maternal expression domain yields evidence for association in autism. Mol Psychiatry. 2003;8(6): 624-34 570.

10. Depienne C, Moreno-De-Luca D, Heron D, Bouteiller D, Gennetier A, Delorme $\mathrm{R}$, et al. Screening for genomic rearrangements and methylation abnormalities of the 15q11-q13 region in autism spectrum disorders. Biol Psychiatry. 2009;66(4):349-59.

11. Fang P, Lev-Lehman E, Tsai TF, Matsuura T, Benton CS, Sutcliffe JS, et al. The spectrum of mutations in UBE3A causing Angelman syndrome. Hum Mol Genet. 1999:8(1):129-35.

12. Bonati MT, Russo S, Finelli P, Valsecchi MR, Cogliati F, Cavalleri F, et al. Evaluation of autism traits in Angelman syndrome: a resource to unfold autism genes. Neurogenetics. 2007;8(3):169-78.

13. Trillingsgaard A, JR OS. Autism in Angelman syndrome: an exploration of comorbidity. Autism. 2004;8(2):163-74.

14. Cook EH CR Jr, Cox NJ, Lord C, Gonen D, Guter SJ, Lincoln A, Nix K, Haas R, Leventhal BL, Courchesne E. Linkage-disequilibrium mapping of autistic disorder, with 15q11-13 markers. Am J Hum Genet. 1998;62(5):1077-83.

15. Nurmi EL, Bradford $Y$, Chen $Y$, Hall J, Arnone B, Gardiner MB, et al. Linkage disequilibrium at the Angelman syndrome gene UBE3A in autism families. Genomics. 2001;77(1-2):105-13.

16. Glessner JT, Wang K, Cai G, Korvatska O, Kim CE, Wood S, et al. Autism genome-wide copy number variation reveals ubiquitin and neuronal genes. Nature. 2009;459(7246):569-73.

17. Veenstra-VanderWeele J, Gonen D, Leventhal BL, Cook EH Jr. Mutation screening of the UBE3A/E6-AP gene in autistic disorder. Mol Psychiatry. 1999:4(1):64-7.

18. Schaaf CP, Sabo A, Sakai Y, Crosby J, Muzny D, Hawes A, et al. Oligogenic heterozygosity in individuals with high-functioning autism spectrum disorders. Hum Mol Genet. 2011;20(17):3366-75.

19. Iossifov I, O'Roak BJ, Sanders SJ, Ronemus M, Krumm N, Levy D, et al. The contribution of de novo coding mutations to autism spectrum disorder. Nature. 2014;515(7526):216-21.

20. Yi JJ, Berrios J, Newbern JM, Snider WD, Philpot BD, Hahn KM, et al. An autism-linked mutation disables phosphorylation control of UBE3A. Cell. 2015;162(4):795-807.

21. Nakatani J, Tamada K, Hatanaka F, Ise S, Ohta H, Inoue K, et al. Abnormal behavior in a chromosome-engineered mouse model for human 15q11-13 duplication seen in autism. Cell. 2009;137(7):1235-46.

22. Smith SE, Zhou YD, Zhang G, Jin Z, Stoppel DC, Anderson MP. Increased gene dosage of Ube3a results in autism traits and decreased glutamate synaptic transmission in mice. Sci Transl Med. 2011;3(103):103ra97.

23. Sanger F, Nicklen $S$, Coulson AR. DNA sequencing with chain-terminating inhibitors. Proc Natl Acad Sci U S A. 1977;74(12):5463-7.

24. Shi YY, He L. SHEsis, a powerful software platform for analyses of linkage disequilibrium, haplotype construction, and genetic association at polymorphism loci. Cell Res. 2005;15(2):97-8.

25. Sole X, Guino E, Valls J, Iniesta R, Moreno V. SNPStats: a web tool for the analysis of association studies. Bioinformatics. 2006;22(15):1928-9.

26. Nackley AG, Shabalina SA, Tchivileva IE, Satterfield K, Korchynskyi O, Makarov SS, et al. Human catechol-O-methyltransferase haplotypes modulate protein expression by altering mRNA secondary structure. Science. 2006;314(5807): 1930-3.

27. Groothuis TA, Dantuma NP, Neefjes J, Salomons FA. Ubiquitin crosstalk connecting cellular processes. Cell Div. 2006:1:21.

28. Yi JJ, Ehlers MD. Ubiquitin and protein turnover in synapse function. Neuron. 2005:47(5):629-32.

29. Sun J, Zhu G, Liu Y, Standley S, Ji A, Tunuguntla R, et al. UBE3A regulates synaptic plasticity and learning and memory by controlling SK2 channe endocytosis. Cell Rep. 2015;12(3):449-61.
30. Sauna ZE, Kimchi-Sarfaty C. Understanding the contribution of synonymous mutations to human disease. Nat Rev Genet. 2011;12(10):683-91.

31. Tindall EA, Petersen DC, Woodbridge P, Schipany K, Hayes VM. Assessing high-resolution melt curve analysis for accurate detection of gene variants in complex DNA fragments. Hum Mutat. 2009;30(6):876-83.

32. Kovac J, Macedoni Luksic M, Trebusak Podkrajsek K, Klancar G, Battelino T. Rare single nucleotide polymorphisms in the regulatory regions of the superoxide dismutase genes in autism spectrum disorder. Autism Res. 2014; 7(1):138-44

\section{Publisher's Note}

Springer Nature remains neutral with regard to jurisdictional claims in published maps and institutional affiliations.
Ready to submit your research? Choose BMC and benefit from:

- fast, convenient online submission

- thorough peer review by experienced researchers in your field

- rapid publication on acceptance

- support for research data, including large and complex data types

- gold Open Access which fosters wider collaboration and increased citations

- maximum visibility for your research: over $100 \mathrm{M}$ website views per year

At BMC, research is always in progress.

Learn more biomedcentral.com/submissions 